\title{
Technology, Globalization, and Economic Policy
}

\author{
Cletus C. Coughlin
}

$\mathrm{T}$ echnological progress raises living standards by creating new goods and allowing existing goods to be produced at lower cost. ${ }^{1}$ Unfortunately, technological change is not without cost. Recent advances in information technology have eliminated many jobs, which has aroused much concern. Neither economic theory nor history, however, suggests that technological change ultimately reduces the total number of jobs available. Rather, the total number of jobs has risen with increases in the labor force. The mechanization of agriculture illustrates this fact: More than seven million U.S. agricultural jobs have been eliminated over the past century; nonetheless, total U.S. employment has risen by more than 100 million.

Economic theory can be used to explain why technological changes do not permanently reduce the total number of jobs. If an innovation enables a firm to make its product or service with fewer employees, some workers might directly lose their jobs. However, the innovation also indirectly creates new jobs. Lower production costs reduce the price of the firm's good or service, increasing the purchasing power of consumers and the profits of the firm's owners. The resulting increase in demand stimulates increased output and provides jobs in other firms.

Through international trade and investment, technological changes have effects throughout the world. In addition to eliminating some jobs, technological changes have shifted some jobs to foreign countries. For example, advances in information and communications technology have made it feasible for firms to locate call centers abroad. The shifting of jobs, combined with increased anxiety about jobs generally, has generated pressures for a political response. Two approaches have been suggested. One approach tries to counteract the market forces underlying globalization, while an alternative approach relies on policies that assist market forces, while providing assistance to those adversely affected.

The fundamental question for policymakers is how to reap the benefits of technological changes, while limiting the adverse effects on those who lose their jobs. Some legislative proposals would inhibit offshore outsourcing by favoring bidders that use only domestic workers. This attempt to save specific jobs raises costs to taxpayers and hinders economic growth.
Restricting the international movement of goods and services will have a similar effect. Numerous studies have shown that trade restrictions provide benefits for some, but are harmful to the nation as a whole. Thus, attempts to inhibit the effects of technological change are potentially very costly.

Offshoring allows firms to produce goods and services at a lower cost than if production were restricted to the United States. Often, the decision on where to locate production is not a choice between producing in the United States or abroad, but rather between outsourcing or not producing at all. For U.S. firms, remaining competitive is necessary for maintaining jobs, many of them highly paid, in the United States.

Rather than attempting to counteract market forces, a better approach is to compensate those who lose their jobs and help them develop new skills. This can be accomplished by expanding unemployment insurance programs to include retraining provisions. The additional benefits allow the affected worker to acquire new skills to take advantage of other job opportunities.

Another proposal would add "wage insurance" to the existing unemployment insurance program. Wage insurance pays dislocated workers, for a period of time, some percentage of the difference between the worker's old wage and new wage. This policy provides a stronger incentive than the existing unemployment insurance program for a worker to become re-employed.

Technological improvements raise living standards. Workers, however, must adapt to this dynamic environment by changing jobs and acquiring new skills. Attempts by the government to counteract the changes caused by technological improvements are likely, in the long run, to make the nation poorer than it need be. On the other hand, policies that assist workers with the process of change will allow the nation to mitigate the costs of change, while still capturing its benefits.

\footnotetext{
${ }^{1}$ Many of the ideas in this cover page were discussed in a speech by William Poole, President of the Federal Bank of St. Louis, on March 25, 2004, at LeMoyne Owen College, Memphis, Tennessee.
} 